\title{
Application of Symbols in Creative Technology Design Taking Mercedes-Benz as an example
}

\author{
Zhang Jing ${ }^{1}$, Liang Yan $^{1}$ \\ ${ }^{1}$ Lanzhou Jiaotong University China
}

\begin{abstract}
Symbols are widely used in all aspects of social life widely used in all aspects of social life, especially in the field of technology. Symbols highlight the characteristics of innovative technology design by transmitting information, increasing recognition, building brands and shaping images. In order to stand out and make great progress in fierce market competition, symbolic creative technology must be regarded as an important content of product design and integrated into it. This paper analyzes the importance of symbol creative change in product design and even brand through examples.
\end{abstract}

\section{The relationship between symbols and product design}

The symbol is a mark used by people to express a particular meaning or to communicate a message in whole society or a field of expertise. The use of symbols is extensive. Product design is a comprehensive and integral creative work, in which symbol design is an important part. In modern life, the symbol has an aesthetic connotation, which not only make the product show its own visual character, but also serve the integral quality of the product.

In order for the public to see excellent symbol design, designers need to constantly investigate, adjust and improve the design in the process of design, so that the designed product is a qualified product. After being putted into the market, symbols will also receive feedback from the market and the experiencer. In order to ensure that the brand occupies a mass market, feedback must be applied to the development and design of the next generation of products. All over the world, these well-known brands and leading enterprises in various fields pay attention to the establishment of their own brand image. Products with distinctive image characteristics tend to account for a large proportion of the market in this field. In this way, these brands have formed their own unique series and family, as well as a fixed and recognized group. Therefore, the application of symbol design in product design influences or determines the shaping and maintenance of enterprise image.

\section{The purpose for which symbols are applied in product design}

In the process of product design, the application of semiotic principles is of practical purpose. In user's using, the relationship between the user's feeling and the meaning expressed, the design concept and structure of the appearance and morphological characteristics is clear.

When it is endowed with different morphological characteristics, the same kind of products will express different meanings and bring different user experiences to the public. The product is not only visual impact, but more to convey information, such as basic functions, using space, operation process and brand image. Since the vast majority of users receive information through visual means, the information is conveyed through the appearance image. In this intuitive way, the feedback designers obtained is the most real and objective.

\section{An example analysis of symbol application in product design- Mercedes-Benz}

Mercedes Benz is a world-famous automobile brand. In the 1950s, the automobile industry boomed, and the major brands gradually formed their own distinct styles. After a hundred years of development, Benz has nearly twenty different classes in the field of cars alone. As an innovative automobile brand, it leads and represents the unique symbol image of high-quality automobiles. The following is a detailed analysis of the symbol language of Mercedes-benz.

\subsection{The structural similarity and modularity of symbol application in products}

"The idea of identifying the features of a pattern through the structural skeleton is of great significance" Arnheim said. The simplification of modeling symbols is carried out according to the structural skeleton. Therefore, the symbol features of the product are mainly composed of the skeleton structure. When different styles of similar products appear, as long as the skeleton structure of their 
products is similar to the skeleton structure of the public perception, then the image will be easily recognized by the public. Nowadays the car is designed in a modular way, but also based on a unified technical architecture, which is why Mercedes has also adopted the new chassis number.

The W124 E-series sedan as an example, the chassis numbers of which ranges from 124.003 to 124.290. And more than 40 models with different engines and transmissions have been designed and produced. Although these engines have undergone different updates from displacement to injection systems, they have always evolved under the Chassis number W124. Due to its unified internal skeleton structure, Mercedes-benz E Series has become the most traditional and most stable and obvious level in the Mercedes family.

The chassis number of Mercedes-benz car family reflects one of the inner cores. The chassis that is the decisive factor that decides the driving mode and space arrangement mode of automobile, has decisive significance in the modeling design of automobile. This is consistent with Arnheim's claim that skeletal structure determines the formal characteristics of external objects. At the same time, the similarity of the chassis of different Mercedes-benz undoubtedly makes the external modeling of this chassis basically similar. This is one of the reasons why we can identify a Mercedes on the road.

\subsection{The shapes of the car are family resemblance}

The research on the modeling symbol of Benz car family takes the head lamp of Benz as an example. Through the development history of Mercedes-benz, we can find that there are two types of headlamp models, including square shape and round shape, in Mercedes-benz cars. The following is the analysis of the most popular mainstream car type (Mercedes-benz) of mass users, and the headlights are summarized as follows :(figure 1)

\begin{tabular}{|c|c|c|c|}
\hline Divide & $\begin{array}{c}\text { Reduced } \\
\text { graph } \\
\text { (headlight } \\
\text { onal } \\
\text { square }\end{array}$ & Reduced graph (headlight) \\
\hline $\begin{array}{c}\text { Traditi } \\
\text { (n) }\end{array}$ & & \\
\hline
\end{tabular}

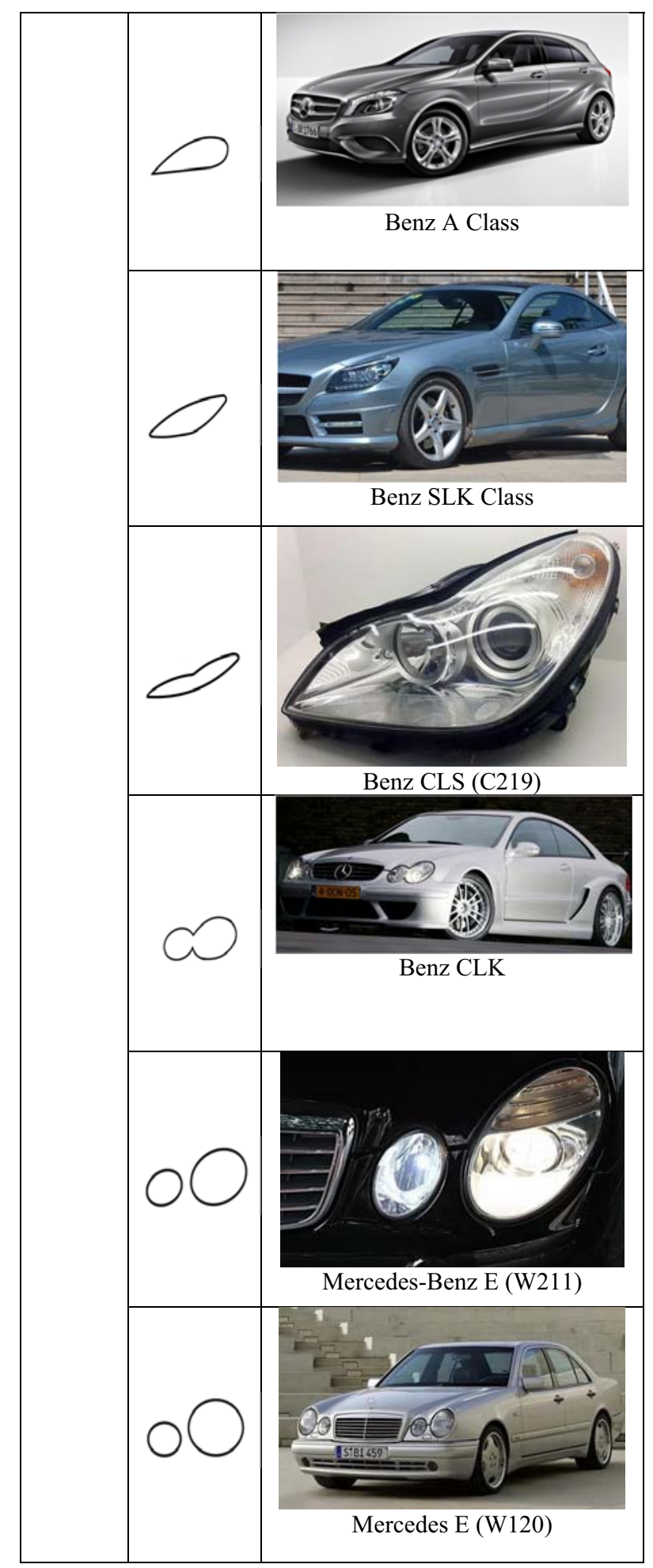

Figure 1 Schematic diagram of the gradual change of the headlamp

Car headlights have two mainly typical forms including square and circular. We can find the irregular headlight pattern is the latest style. In the past two years, square and round headlamps have been widely used. With the change of time, the square traditional lamp will change to the irregular organic form, while the circular lamp will also change to the irregular organic form. When the two traditional forms develop into irregular forms, a batch of car headlights with significant 
differences from the traditional shapes will be produced. But the inheritance relationship is also obvious in the new shape and the new form of innovation.

According to the class of each type of headlamp, we can find the generality of the symbol of car family. The same headlights can be found on E-class cars as well as CL or CLK class cars, which is the core of the family resemblance. We can compare car headlights to people's eyes. In a family, although the eyes of each member are not the same shape, the look is very similar. Therefore, If the change of the mainstream headlight is regarded as a linguistic fragment of the shape of the BENZ headlight, through this segment, we cannot predict the shape of the future, but can trace its past history.

The following will specifically analyze the formation and evolution of circular and square headlamp modeling symbols.

By horizontal comparison of time, the round headlights are earlier than the square ones. For example, the Mercedes-Benz series, which was dominated by round headlights in the 1950s, but still shows up in the GSeries SUVs.

In 1930, designers began to break through from function and form. In 1934, the $510 \mathrm{k} \& 540 \mathrm{k}$ introduced by Mercedes-Benz can be observed in the change of headlight arrangement :(figure 2).

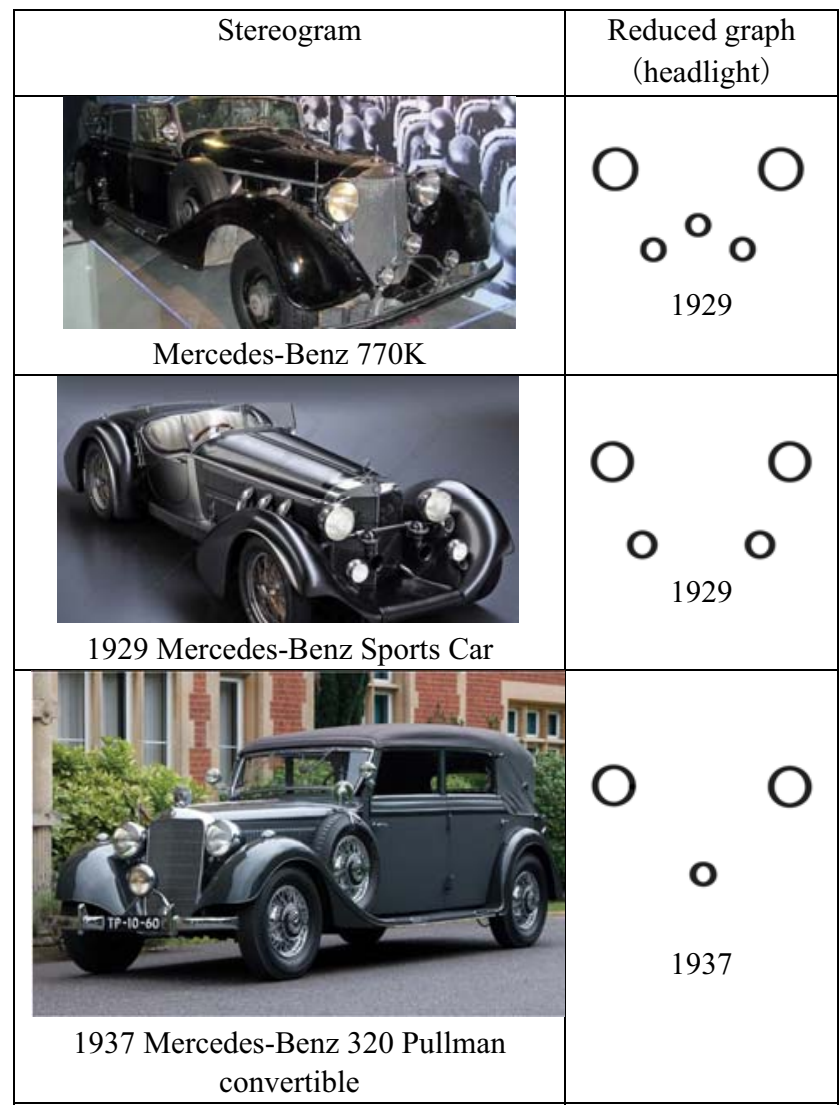

figure 2 Schematic illustration of the arrangement of early headlights

In the 1951 Model of Mercedes-Benz220, we were astonished to find that the separation of headlights and body was over. At the same time, the headlights began to be embedded into the shell of the front of the car. This shows stylist begins to notice headlamp modelling design. In the $300 \mathrm{~S}$ model, double round headlights were appeared (Figure 3). At that time, the small headlights were still outside the body of the car, but which was a breakthrough in styling. It also became the forerunner of the E series of double round headlights.

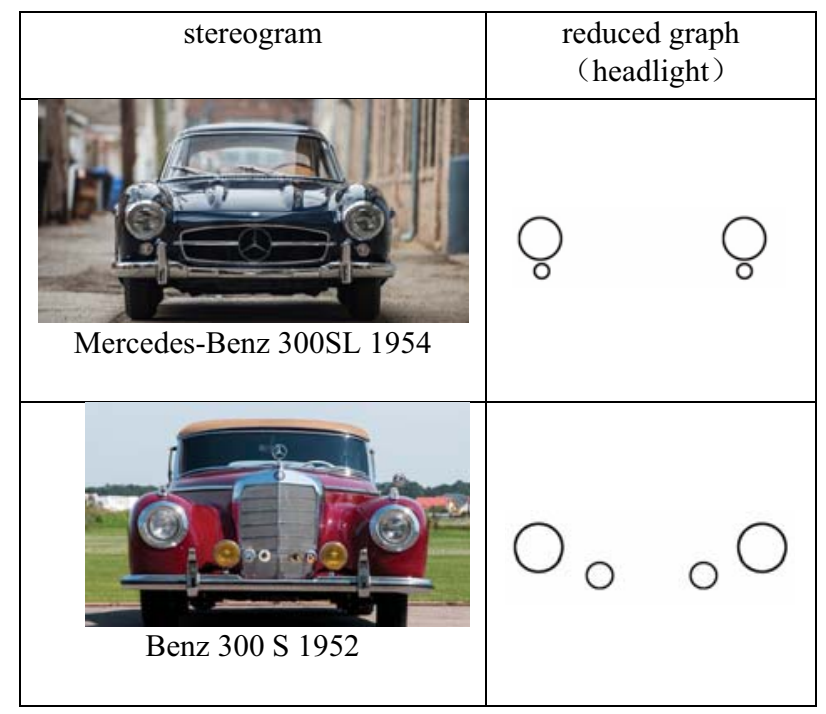

Figure 3 The appearance of double headlamps

The 300SL (W198) Gull wing doors, was introduced in 1954. (Figure 4) A further change in the headlight design can be seen on this car, with the elliptical headlight starting to appear.

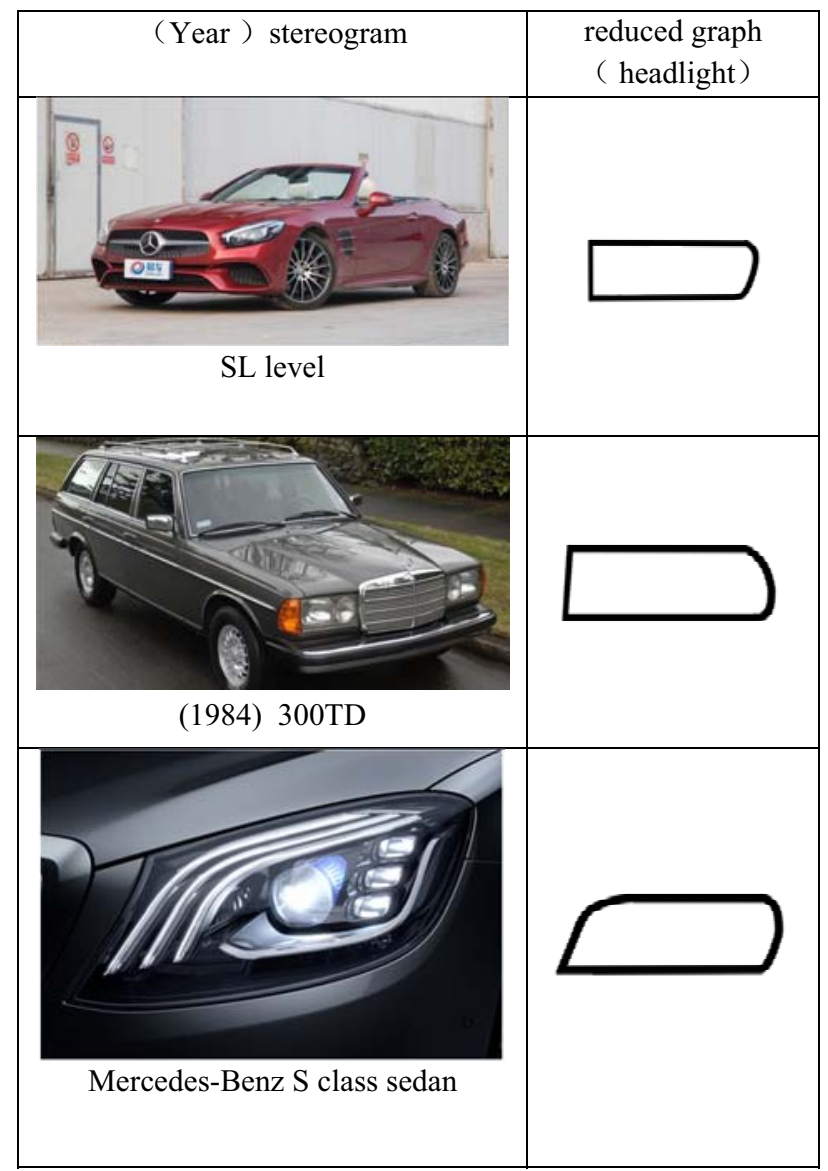




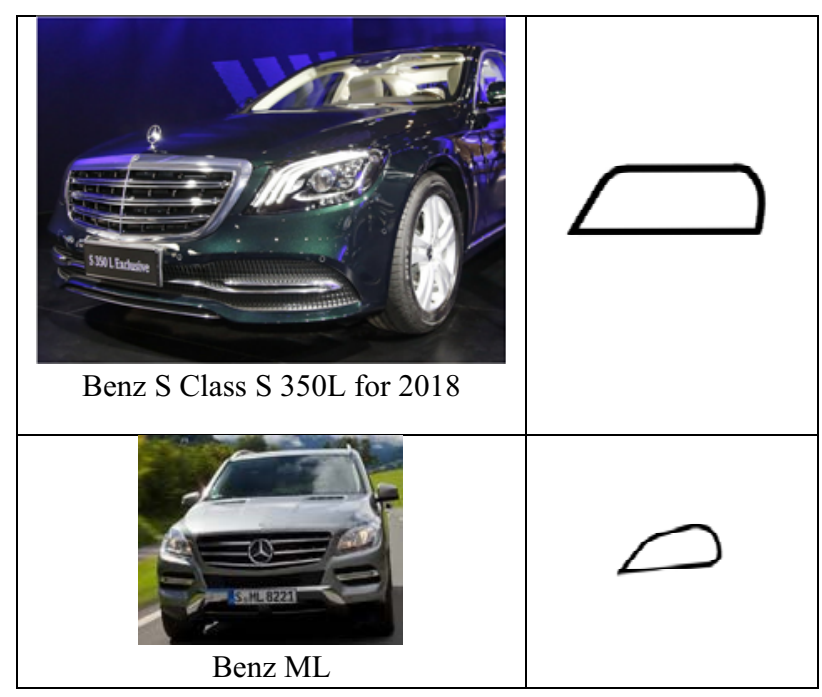

Figure 4: Headlamps

In 1959, twin round headlights embedded in the body were used on the model 200s. In 1960, elliptical headlights began to appear in public view. In the 1970s, with the prevalence of idealism, absurdity, abstraction, nihilism and detachment of modernism, Mercedes Benz launched 350SL-560SL, opening a new era of square headlights. When Mercedes-benz introduced the E200E55AMG, it rediscovered the classic, as shown in fig.5. At the same time, the double round headlights in the new model design also stimulated consumption, so that consumers no longer satisfy the traditional form. In addition, the later period of the car brand in the modeling also have reference. BMW has some similarities with Benz in styling design. Therefore, Mercedes-benz leads the German car elegant, high-performance brand image. Hyundai cars in South Korea pay more attention to styling. Meanwhile, the headlights of this car are more easily associated with the double round headlights of Mercedes-benz.

\subsection{Summary}

Through analysis, Mercedes Benz can always take a leading position in the competitive world market environment, because it has the core symbol of the brand (visual identification function, form, language, etc.). With the change of environment, regardless of the evolution and innovation of product appearance, the modeling symbols of these core products have never been abandoned, and have played an important role in the "product family gene" for a long time. Through research and analysis, the general rule of product symbol language design and application is to integrate Lines, colors and local details, logos that represent brand characteristics into the appearance of the product. This will create a strong influence of brand and visual impact of the product.

\section{Conclusion}

Nowadays, in the process of design, manufacturing and practice, the famous designers and brand manufacturers regard the appearance design of products as an important means to show the basic functions, express the original intention of design, highlight the value of products and flout the brand concept. This phenomenon makes the concept of "symbol modeling" give birth to new connotation in product design. The symbol design in product design is no longer the pure form design which is disjointed with the design concept as understood by designers at the beginning of the rise of the industry. In that period, the combination of form, function and concept could not properly express the subjective design intention. In order to advertise themselves, enterprise brands can be printed various pictures and text of colors and styles which do not match with the product. Nowadays, product appearance design has developed into injecting enterprise (brand) cultural concept into the appearance of products through refinement, structure and restructuring. In terms of market share, the products made in this way really play the role of the brand.

In the future, when we are engaged in the study and research of product design, we should closely combine people's use demands, operation modes, product functions, design concepts and other symbols that can better highlight the product personality through design. At the same time, this approach is applied to every design proposal.

\section{REFERENCES}

1. Zhang Xianrong. Design semiotics M]. Beijing: Chemical Industry Press ,2004

2. Hu Fei Yang Rui. Design Symbols and Product Meaning [M]. and Beijing: China Construction Industry Press ,2003

3. Wang Wangyu. Automotive design. Beijing: Machinery Industry Press ,2004

4. Huang Tianze Golden Mausoleum. Automobile body structure and design. Beijing: Mechanical Industry Press , 1997

5. Ren Xiaodong $\mathrm{Gu}$ Xingcheng. Import car brand manual. Shanghai: Shanghai Science and Technology Press, 2003

6. Reengineering the Corporation-A manifesto for Business Revolution. James Champy, Michael Hammer. New York. 1993

7. Post Capitalist Society. PeterF. Durcker. Harper Collins. 1993

8. The process audit. Hammer Michael. Harvard Business. 2007

9. Liu Chuanbing. Aesthetics Development and Car Design's Century Resonance [D].] in China Jiangnan University ,2005.

10. Sun Wei. A Study on the Application of Symbolic Elements in the Innovation of Automobile Modeling Design [D].1 Jiangnan University ,2008.

11. Huang Zhong. A Study on the Evolution of Automobile Form of the Three Major Automobile Brands in Germany [D].1 Hunan University ,2005. 
12. Huang Zhong. A Study on the Evolution of Automobile Form of the Three Major Automobile Brands in Germany [D].1 Hunan University ,2005.

13. Zhang Yan, Yi Shun. Application of Morphological Language Symbols in Product Modeling Design [J].1 Beauty and the Times (first half)2009(07):91-93. 